NISTIR 7268

\title{
Workshop on the Evaluation of a Tactical Decision Aid Display
}

\author{
William D. Davis \\ Robert Vettori \\ Paul Reneke \\ Lori Brassell \\ David G. Holmberg \\ Jodi Kostecki \\ Jessica Kratchman
}


NISTIR 7268

\section{Workshop on the Evaluation of a Tactical Decision Aid Display}

William D. Davis

Robert Vettori

Paul Reneke

Lori Brassell

David G. Holmberg

Jodi Kostecki

Jessica Kratchman

Building and Fire Research Laboratory

Gaithersburg, Maryland 20899

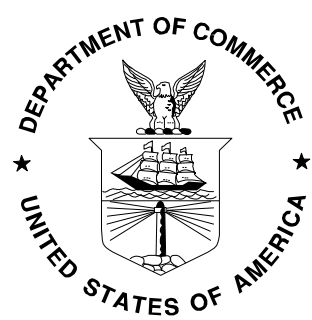

U.S. DEPARTMENT OF COMMERCE

Carlos M. Gutierrez, Secretary

TECHNOLOGY ADMINISTRATION

Michelle O'Neill, Acting Under Secretary of Commerce for Technology NATIONAL INSTITUTE OF STANDARDS AND TECHNOLOGY

William A. Jeffrey, Director 


\section{Table of Contents}

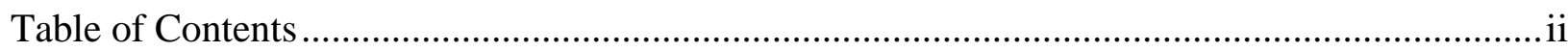

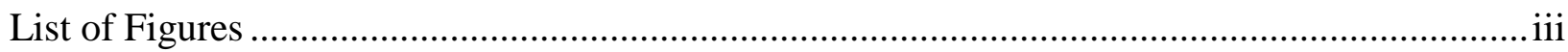

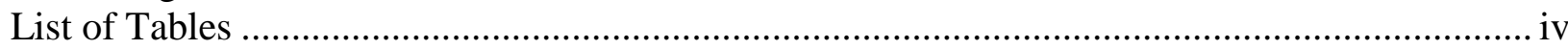

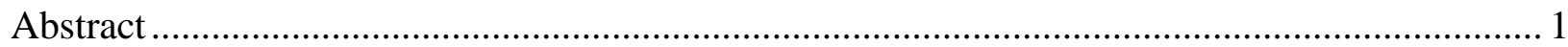

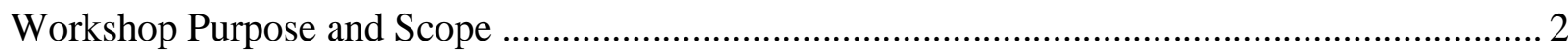

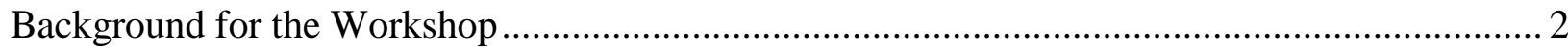

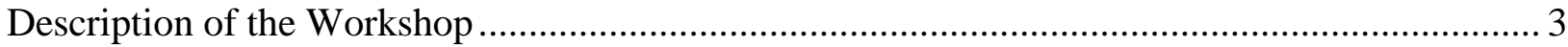

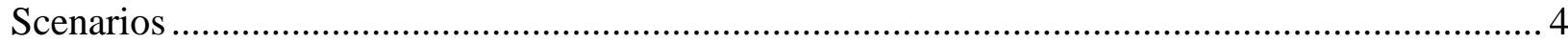

Scenario 1 - Fire in a Hospital Waiting Room ........................................................ 4

Scenario 2 - Building Break-In and Set Fire ............................................................. 5

Scenario 3 - Fire in a Two Story Single-Family Dwelling ............................................... 5

Scenario 4 - Emergency Medical Call to a Shopping Mall ...................................................... 5

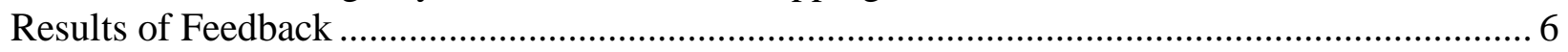

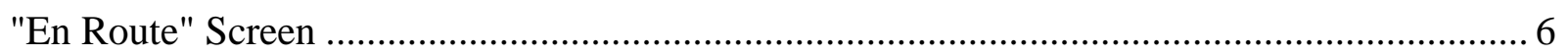

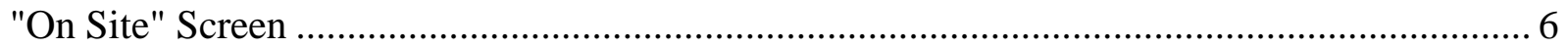

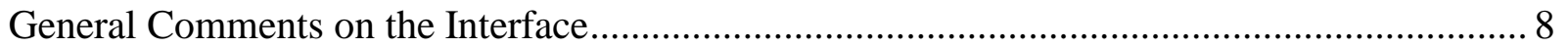

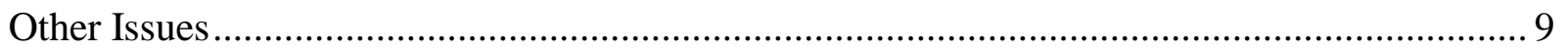

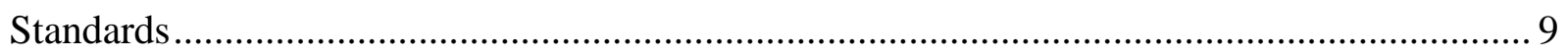

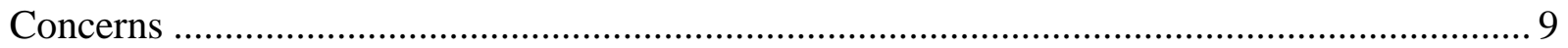

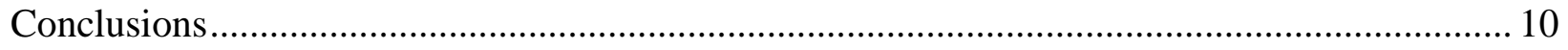

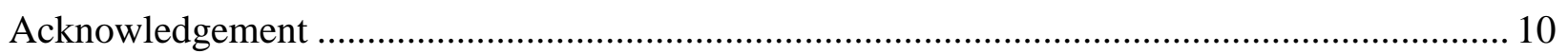

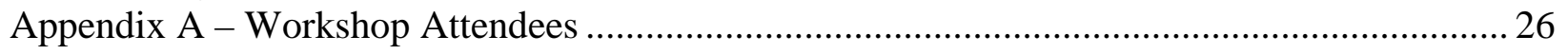

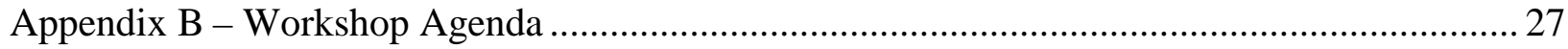

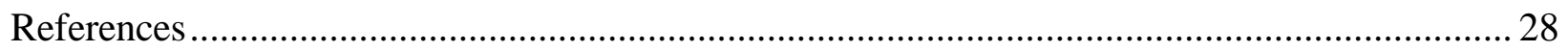




\section{List of Figures}

Figure 1 "En Route" screen for the hospital fire scenario. The button on the left side of the figure titled "On Site Screen" allowed the user to toggle back and forth between the "En Route" and "On Site" screens.

Figure 2 "On Site" screen for the hospital fire scenario after the first heat sensor has activated. The button on the left side of the figure titled "En Route Screen" allowed the user to toggle back and forth between the "En Route" and "On Site" screens

Figure 3 "On Site" screen for the hospital fire scenario after seven events have been listed in the event list. The button on the left side of the figure titled "En Route Screen" allowed the user to toggle back and forth between the "En Route" and "On Site" screens

Figure 4 "En Route" screen for Building Break In and Set Fire scenario. The button on the left side of the figure titled "On Site Screen" allowed the user to toggle back and forth between the "En Route" and "On Site" screens.

Figure 5 "On Site" screen for Building Break In and Set Fire scenario. The button on the left side of the figure titled "En Route Screen" allowed the user to toggle back and forth between the "En Route" and "On Site" screens.

Figure 6 Final "On Site" screen for Building Break In and Set Fire scenario. The button on the left side of the figure titled "En Route Screen" allowed the user to toggle back and forth between the "En Route" and "On Site" screens.

Figure 7 "En Route" screen for the Fire in a Two Story Single Family Dwelling scenario. The button on the left side of the figure titled "On Site Screen" allowed the user to toggle back and forth between the "En Route" and "On Site" screens.

Figure 8 "On Site" screen for the Fire in a Two Story Single Family Dwelling scenario. The button on the left side of the figure titled "En Route Screen" allowed the user to toggle back and forth between the "En Route" and "On Site" screens

Figure 9 "On Site" screen for the Fire in a Two Story Single Family Dwelling scenario. The button on the left side of the figure titled "En Route Screen" allowed the user to toggle back and forth between the "En Route" and "On Site" screens

Figure 10 Final "On Site" screen for the Fire in a Two Story Single Family Dwelling scenario. The button on the left side of the figure titled "En Route Screen" allowed the user to toggle back and forth between the "En Route" and "On Site" screens.

Figure 11 "En Route" screen for the Emergency Medical Call to a Shopping Mall scenario. The button on the left side of the figure titled "On Site Screen" allowed the user to toggle back and forth between the "En Route" and "On Site" screens.

Figure 12 "On Site" screen for the Emergency Medical Call to a Shopping Mall scenario. The button on the left side of the figure titled "En Route Screen" allowed the user to toggle back and forth between the "En Route" and "On Site" screens. 


\section{List of Tables}

Table 1 Event list for a Fire in a Hospital Waiting Room scenario.......................................... 11

Table 2 Event List for Building Break In and Set Fire scenario ........................................... 12

Table 3 Event list for Fire in a Two Story Single Family Dwelling scenario ............................ 13 


\section{Abstract}

On July 26, 2005, the National Institute of Standards and Technology (NIST) conducted a workshop consisting of fire service and fire safety personnel that had two objectives. The first, was to give the attendees a presentation of the history and present status of the project entitled "Building Tactical Information System for Public Safety Officials". The second objective was to have the group participate in a hands-on exercise, where they were able to work with and evaluate the present system of first responder information displays which are designed to provide real time building and emergency information to incident command and dispatch centers. Their evaluations and recommendations for improvements of the current displays are presented in this document.

Key Words: building information, elevators, emergency preparedness, emergency responder, emergency response, fire alarm system, fire detection, homeland security, incident command 


\section{Workshop Purpose and Scope}

On July 26, 2005, the National Institute of Standards and Technology (NIST) conducted a workshop on information needs of emergency responders. This workshop was organized to support a Department of Justice, Office of Community Oriented Policing Services (COPS) funded project entitled, "Building Tactical Information System for Public Safety Officials". The purpose of this workshop was to meet with the community of emergency responders who are responsible for public safety with the focus on the presentation and use of data contained in building systems. The goal of the Tactical Decision Aids Interface Workshop was to have the attendees evaluate the presentation of real time building information as well as the information itself.

\section{Background for the Workshop}

Many large buildings have building automation systems that manage environmental systems, security systems, fire protection systems, energy management systems, elevator systems, etc. These systems process and store a large amount of data that is potentially useful to emergency responders. Such data would include floor plans of the building, sensor data from smoke and heat detectors, gas detectors, motion detectors, etc. Other information may include data from heating ventilation and air conditioning (HVAC) systems, door and elevator access, room occupancy, lights, and cameras. On May 3, 2004, NIST conducted a workshop to identify information needs for emergency responders during building emergencies [1]. That workshop brought together emergency responders with the goals of sharing the vision of how the availability of building information can impact emergency response, and to gain from attendees guidance on what specific building information would be of greatest benefit to public safety officials, as well as how to present it, and with what security measures.

Critical building information needs to be sent to and displayed on a wide variety of display devices, from high-resolution screens at dispatch centers, wireless devices for notebook computers in fire apparatus or police cars, and handheld devices. In order to assure interoperability of the information (or data) transmissions, requirements for the data and presentation formats must be defined as well. In the building industry, there is ongoing work to address building controls interoperability between different manufacturers, including the work on the Building Automation and Control Networks (BACnet) standard at NIST [2], and more recently work to provide building data to those outside the building. In the case of an emergency event, fire, police, and other emergency personnel arrive at a building and are faced with the need to quickly appraise the situation, find occupants, locate problems, determine the best way of dealing with the emergency, deploy resources, and then update tactical information as the event progresses.

Since the September 11, 2001 attacks on the World Trade Center and the Pentagon, there has been a focused effort to improve prevention, preparedness, response, recovery, mitigation, and coordination processes across the country. However, a comprehensive approach to providing building tactical information to building incident responders, applicable at all jurisdictional 
levels and across functional disciplines, would further improve the effectiveness of emergency response providers and incident management organizations across a full spectrum of potential building incidents and hazard scenarios. Such an approach would aid in coordination and cooperation between public and private entities in a variety of domestic incident management activities.

A list of workshop attendees is provided in Appendix A - Workshop Attendees. The workshop agenda is given in Appendix B - Workshop Agenda.

\section{Description of the Workshop}

The attendees worked with laptop computer interfaces and evaluated the presentation of information on four different scenarios that require Fire Department response. The four scenarios were: (1) a fire in a hospital, (2) a person breaking into a laboratory building and setting fire to a room on the third floor, (3) a fire on the second floor of a two story single family dwelling, and (4) an emergency medical call inside a large shopping mall. The displays were presented on laptops since these are similar to the equipment that is currently installed in some fire department apparatus and incident command vehicles.

For each scenario two computer screens of information were presented. The first screen was titled an "En Route" screen. This screen gave a plan view of the building footprint and surrounding area. Streets that surround the building were indicated along with information such as location of fire hydrants, fire department connections to the building standpipe and automatic sprinkler systems, and location of entrances to the building. Other information that may be displayed would be the location of interior stairwells, elevators, and an indication if hazardous materials are present in the building. Figure 1 is an example of an "En Route" screen. The second screen, titled "On Site" would give detailed information regarding the interior of the building. An example of an "On Site" screen is Figure 2. This figure shows the third floor interior view of the hospital. The upper left of this screen has buttons labeled "Fire", "Hazards", and "Building". By pressing the "Fire" button, additional information such as the location of interior standpipe connections would be displayed, information on fire wall ratings, and location of fire fighting equipment and emergency medical services equipment would be shown. The "Hazard" button would give information on building hazards and information on hazardous materials that would be present in the building. The "Building" button gives information regarding security, elevators, utility shut offs, generators, and the location of materials that may be of importance to building owners. The "Zoom In" and "Zoom Out" buttons allow the view to be magnified. The arrow buttons allow the user to scroll through the screen. A reset button is available that would bring the scene back to a default setting. Below this is a method for the user to move to different floors in the building. Below this is the event list. Within the event list all changes in the sensors of interest and room conditions would be listed. Figure 2 shows the "On Site" screen for the hospital scenario when the first heat sensor is activated which shows up on the computer screen as the first event in the event list. Figure 3 shows the same computer screen after a longer period of time. In this figure seven sensor events have occurred and have been listed in the event list. The top portion of each screen gives additional information on the 
building and incident. Information may include the building name and address, location of the fire within the building, estimate of how long the fire has been burning, building occupancy, is the building sprinklered, etc. A "N/A" indicates that information is either not available or does not pertain to the incident.

The attendees were asked to run through each scenario multiple times to determine what information was available and to get comfortable with the way the information was presented. They were asked to evaluate the interface by noting:

- What worked.

- What did not work.

- Was the information useful.

- What other information would you need that was not provided?

- What is missing?

- Was the layout acceptable?

- Provide suggestions for improving the interface.

- What other scenarios might demand other kinds of information or different interface design?

Other general questions asked of the attendees were:

- If you have a system such as this, how would it impact your operations in the field, at the emergency dispatch center?

- What additional work load would be added to your incident command operations in the field?

- What additional training would be required of your field personnel and your emergency dispatch center personnel?

- What questions do you have that have not been addressed?

\section{Scenarios}

\section{Scenario 1 - Fire in a Hospital Waiting Room}

The first scenario depicts a fire that has started in the third floor waiting room of a hospital. Figure 1 depicts the "En Route" screen. Figure 2 depicts the "On Site" screen and indicates the first sensor event under the event list as a heat detector activation in the third floor waiting room. Both of these screens would be available to responding fire, police, emergency medical service apparatus and also to the emergency dispatch center. As the incident progresses real time information from the building systems is sent to the emergency responders and the emergency dispatch center. Figure 3 shows the display of the third floor "On Site" screen after seven events. On the display, the rooms change colors as sensors report the changing conditions within the rooms. In Figure 3 the waiting room is depicted in yellow and the event list indicates that the sensors are reporting that within this room there is a possible toxic/thermal hazard. The two rooms opposite the waiting room are reporting limited visibility conditions and are depicted in green. A complete record of the event list for this scenario is presented in Table 1. 


\section{Scenario 2 - Building Break-In and Set Fire}

This scenario simulates the unauthorized entry of an individual into a laboratory building. The individual proceeds via the elevator to the third floor of the building, sets fire to one of the laboratories, and then exits the building. The "En Route" screen that would be available to the emergency responders and the emergency dispatch center is shown in Figure 4. An example of the "On Site" screen is shown in Figure 5. The event list is given in Table 2.

The first 15 events for this scenario do not pertain to the fire department. They describe through the use of door, elevator, and motion sensors the path taken by the intruder. This demonstrates the use of this system for law enforcement purposes. The final "On Site" screen is shown in Figure 6. It shows that the room in which the intruder had set on fire has gone to flashover, the hall outside this room has a toxic/thermal condition, the room behind this room also has a toxic/thermal condition and the two halls in blue have possible hazardous conditions.

A ten minute video of this simulation is available from NIST. The video reveals the interaction between an operator at the emergency dispatch center and the responding police and fire apparatus.

\section{Scenario 3 - Fire in a Two Story Single-Family Dwelling}

This scenario depicts a fire starting in a second floor bedroom of a two story single-family dwelling. The "In Route" screen is shown in Figure 7 and the initial "On Site" screen is shown in Figure 8. This screen shows the location of the initial alarm and is also listed in the event list. The entire event list for this scenario is given in Table 3. An "On Site" screen after 6 sensor events is shown in Figure 9 and the final "On Site" screen after all the events have occurred is shown in Figure 10.

\section{Scenario 4-Emergency Medical Call to a Shopping Mall}

This scenario is a simulation of an emergency medical call in a large shopping mall. These shopping malls may have several anchor stores and contain many entrances not only to each anchor store, but to the common areas of the mall itself. Pinpointing the location of an area or store inside a large building such as this is difficult, especially for one who may not be familiar with the building. This situation may occur during a busy time when many emergency medical service units that normally respond to this building may be on other incidents and a unit from a much greater distance would have to respond. The individuals on this unit may not be familiar with the building. Since the floor plans and plan view of the building are stored in the building itself they can be transmitted along with the location of the incident within the building to the responding apparatus and the emergency dispatch center. The "En Route" screen for this scenario is shown in Figure 11 and the "On Site" screen in Figure 12. 


\section{Results of Feedback}

\section{"En Route" Screen}

- Need to show which stairwells go to the roof and basement of the building.

- Show the outside connections to standpipe and automatic sprinkler systems.

- List the contacts for the building engineer or responsible persons.

- A listing of possible items that would be detrimental to emergency responders, hazards, dangerous conditions. This would be a local decision made by individual Fire Departments.

- A map of the complex that shows more of the area, where an officer can determine the best access for apparatus and also best foot access to the buildings.

- Designate building sides on the screen with the commonly used Side A, Side B, Side C, Side D methodology.

- Show North, South, East, and West on the screen. Place a compass rose on the screen or simply an arrow that indicates the North direction.

- A map that would show where the fire apparatus is and a route to the emergency.

- The initial sensor indicator was to small and hard to see on the computer screen; a larger more abrupt indication is needed.

- Indicate the distance between surrounding buildings.

- Indicate the building name and the names of the surrounding streets.

- List life safety concerns of the building and what is detrimental to fire fighters, allow system for fire department to rank hazards.

- Have the ability to show a photo of the building, preferably all four sides.

\section{"On Site" Screen}

- For the floor displays, if the user switches to another floor to look elsewhere he/she should not lose the fire floor, a method needs to be there to instantaneously return to the fire floor.

- Need to see the detectors in alarm more clearly. Is it a smoke alarm or heat alarm? Suggested using "S" for a smoke detector, "H" for a heat detector, and "WF" for a water flow alarm.

- For each room have instant access to all information.

- A labeling scheme is needed.

- Stairwells need to be labeled.

- Room numbers need to be on the floor plan. They are on the event list, but not on the floor plan.

- Zones need to be identified for such items as HVAC, firewalls, areas of refuge, security, etc.

- Mechanical rooms need to be clearly identified.

- Generator locations need to be identified.

- On the screen, North, South, East, and West need to be indicated. Place a compass rose on the screen or simply an arrow that indicates the North direction. 
- Some participants thought the colors did not work and were too many. One participant suggested yellow for toxic, red for deadly, and flashing red for a flashover condition. The use of a distinctive color for a chemical biological hazard was discussed. Some participants did not think that a color for smoke was necessary.

- Actual camera views of the building would be beneficial. For a high rise, a side view showing a vertical presentation would be helpful. If the building is very tall, display this presentation in sections. The same may hold true for very large low rise buildings.

- Need to indicate which stairwells are pressurized.

- Indicate which fire doors are not shut.

- Need to have ready access to information on other floors. Definitely not a menu with a "go" button. Need buttons that allow getting to floors above and below the emergency.

- Would like to keep the fire floor in view even as they go to an alert or view other floors.

- Do not show the Event List unless it is needed, it wastes screen space and the Incident Commander will not have time to study it. The Incident Commander is busy with many other tasks and will only have time to catch the visually eye catching stuff.

- If the Event List is kept, have new events flash in one color for a specified time, then stop flashing and change to another color.

- The standpipe classification should be specified.

- Automatically show interior stand pipe connections.

- Show location of individuals with disabilities.

- Denote which wing of the building is being viewed, not just the building name.

- Give a description of the floor or room type. Is it a patient floor, primarily laboratories, or operating rooms, etc?

- Have continuous notification of utilities such as electrical, gas, HVAC, other mechanical systems. They get lost in the present Event List.

- Have the ability to break up a building into sectors based on firewall locations. Others thought that the fire rating information would not be very beneficial during fire fighting operations.

- Give indications of fire door status.

- Can we note system faults such as a dead sensor?

- Would like to see the incorporation of information about individuals with disabilities.

- Would like to have all standpipe, hazard and mechanical information come up automatically.

- Would like to note any unaffected stairways and elevators for evacuation decisions.

- Would like to see sprinkler activation and flow in gallons/minute to help determine how much more water is needed.

- Instead of indicating "building occupancy" use the term "current occupancy".

- The legend should be on the screen at all times.

- For a medical emergency note the size of the elevator or stairway. This will help the crew in making decisions on where to take the stretcher.

- Under location of fire fighting equipment have the ability to add items that may be specific to a particular building or complex. For example a subway station may have specialized equipment for evacuating civilians. 


\section{General Comments on the Interface}

- A "Local language" or "Street language" attached to the building data set, or the application is customizable so that the local Fire Department can write in the display the language for interpreting standard language. For example, instead of using the term "Type V" for building construction, use a term such as wood frame, or steel construction.

- If something happens outside the view of the floor plan that is being shown then there needs to be a method of alerting the user. The Event List may not be useful. Maybe tabs that flash to indicate changes, the flashing stops after acknowledgement.

- When an alert occurs, have a flashing tab to indicate the alert and have the screen jump to the location of the alert, but with a ready return to the existing screen.

- Have fixed buttons or tabs across the top of the screen for such items as HVAC, video, elevators, utilities, security, etc. and buttons or tabs on the side of the screen that are specific to the ones along the top.

- Need to easily filter the information to your needs. Have the ability to turn off certain displays such as security, motion detectors, video, room numbers, etc.

- When the curser is passed over an icon have the information associated with that icon automatically displayed - such as room information, alarm information, hazard information, occupancy, etc. When the cursor is moved off of the icon the information is erased.

- Need to have touch-screen or voice recognition option-not just for mobile unit, but dispatch centers also. Desktop applications with the use of a mouse are useful for administrative or code official use.

- Make an option for screen printout so that situations may be compared at different times.

- Have a "text" printout of events for later discussion/learning tool.

- Would like to be able to choose information to print for a handout. When an assignment is given to an individual or group, have the ability to print out the necessary information so they can take it with them.

- If flashing tabs are used for notification instead of an event list, filter events based on priority.

- The "En Route" maps with roadways and hydrant connections were helpful for the initial responding units.

- Larger buttons or tabs are needed.

- For the Emergency Medical Call scenario at the Shopping Mall there was not enough information displayed. What was the patient condition? What was the store name? Where is the best access to the store?

- If the elevator is in safe mode indicate which floor it is on. If there is smoke in the lobby can we note the phase the elevator is in?

- Can we track people through the building?

- Want a section where other information can be added manually.

- Want to keep the program simple.

- Would like the ability to tile the screens.

- When electric, gas or other utility is shut off, that should generate an event.

- Filtering of the event list by some prioritizing method. For the hospital scenario there were 30 events in 5 minutes. 


\section{Other Issues}

- What the best access is should be determined by the user or the incident commander based on information he/she has.

- There are security issues on public safety networks. What is police information, fire department information, what information is shared?

- Need scalable layering of information to provide a minimum most useful set of information to clients on a low bandwidth connection with higher rate connections getting a richer set of information.

- What about present buildings that will never be "Smart". Can there be just an indication of detector alarm locations.

- Integration of other applications, such as Mobile Data Computers, with these systems.

- The possibility of displaying the Fire Department's Standard Operating Procedures on the screen if desired.

- Is there a possibility of interacting with multiple "situations" at one time from a single computer.

- Develop an option that will allow task assignments to be delegated to a fire fighter while assessing the information.

- How can information gained from field inspections be used to update the system?

\section{Standards}

- There is a need for a national standard for fire announcements. There needs to be standards for voice, horns, bells, and strobes.

- Need some standard on what qualifies as an alert or event that will be displayed.

- How is the static data synchronized in the system? Is a standard needed for that?

- Need a standard process or guideline for the process of propagating information changes.

- Need to address a standard interface to Geographic Information Systems (GIS).

- Although a region or group of fire departments may be based on one type of mapping system, terminology within the systems may be different. One jurisdiction may say "Street Name" and another may say "Road Name" such that the Data Bases cannot be merged.

- Each community should have the flexibility to add information they feel is important.

- Standardize a basic set of information or that is sent, not the display.

\section{Concerns}

- Information overload.

- Time is of the essence; they want quick, simple, pertinent information.

- Will this system create larger delays?

- How much training will be required for field personnel and emergency dispatch center personnel? 
- Security of the information that is being broadcast to fire, police, emergency medical services apparatus and to emergency dispatch centers?

- Local Fire Departments have a lot of pride in knowing the buildings in their assigned area. There is a concern that this program could promote laziness in learning the buildings. Also concerned this would lead to dependence on a system that cannot track construction and renovations.

\section{Conclusions}

The participants evaluated the computer interface and presentation of data on all four scenarios multiple times. Participants gave feedback and made recommendations for improvements to the tactical decision aids interface and data that is presented. NIST has grouped and consolidated the recommendations in the previous section. NIST's next step will be to incorporate as many of these recommendations as possible and have a live, real time demonstration of the interface. This will include mounting the computers in fire apparatus, incident command vehicles, and the emergency dispatch centers and have the fire service and fire safety personnel evaluate the system in as real a scenario as possible.

\section{Acknowledgement}

This workshop was sponsored in part by the Department of Justice Community Oriented Policing Service (COPS) via the NIST Office of Law Enforcement Standards (OLES) to advance the development of the Building Tactical Information System for Public Safety Officials project. 
Table 1 Event list for a Fire in a Hospital Waiting Room scenario.

Event Time Description of event

\begin{tabular}{|c|c|}
\hline 11:02:56 PM & Heat sensor activated - level 3 waiting room \\
\hline 11:05:11 PM & Heat sensor activated - room 379 \\
\hline 11:06:11 PM & Potential hazard - level 3 waiting room \\
\hline 11:06:42 PM & Visibility limited - level 3 waiting room \\
\hline 11:07:30 PM & Toxic/thermal hazard - level 3 waiting room \\
\hline 11:08:47 PM & Visibility limited - level 3 EENT room \\
\hline 11:08:48 PM & Visibility limited - room 374 \\
\hline 11:09:19 PM & Visibility limited - room 376 \\
\hline 11:09:20 PM & Visibility limited - room 378 \\
\hline 11:09:21 PM & Visibility limited - room 380 \\
\hline 11:09:22 PM & Visibility limited - room 382 \\
\hline 11:09:23 PM & Visibility limited - room 384 \\
\hline 11:09:24 PM & Visibility limited - room 375 \\
\hline 11:09:25 PM & Visibility limited - room 377 \\
\hline 11:09:26 PM & Visibility limited - room 379 \\
\hline 11:09:27 PM & Visibility limited - room 381 \\
\hline 11:09:51 PM & Visibility limited - room 383 \\
\hline 11:09:52 PM & Visibility limited - room 385 \\
\hline 11:09:53 PM & Visibility limited - section E-3 \\
\hline 11:09:54 PM & Visibility limited - section D-3 \\
\hline 11:10:10 PM & Visibility limited - room 313 \\
\hline 11:10:55 PM & Toxic/thermal hazard - level 3 EENT room \\
\hline 11:10:56 PM & Toxic/thermal hazard - room 374 \\
\hline 11:10:57 PM & Toxic/thermal hazard - room 376 \\
\hline 11:10:58 PM & Toxic/thermal hazard - room 378 \\
\hline $11: 11: 22 \mathrm{PM}$ & Toxic/thermal hazard - room 380 \\
\hline 11:11:23 PM & Toxic/thermal hazard - room 382 \\
\hline $11: 11: 24 \mathrm{PM}$ & Toxic/thermal hazard - room 384 \\
\hline $11: 11: 25 \mathrm{PM}$ & Toxic/thermal hazard - room 375 \\
\hline 11:11:26 PM & Toxic/thermal hazard - room 377 \\
\hline $11: 11: 27 \mathrm{PM}$ & Toxic/thermal hazard - room 379 \\
\hline $11: 11: 28 \mathrm{PM}$ & Toxic/thermal hazard - room 381 \\
\hline $11: 11: 29 \mathrm{PM}$ & Toxic/thermal hazard - room 383 \\
\hline $11: 11: 51 \mathrm{PM}$ & Toxic/thermal hazard - room 385 \\
\hline $11: 11: 52 \mathrm{PM}$ & Toxic/thermal hazard - room 313 \\
\hline 11:11:53 PM & Visibility limited - section B-3 \\
\hline $11: 11: 54 \mathrm{PM}$ & Flashover conditions - level 3 waiting room \\
\hline 11:12:19 PM & Visibility limited - room 323 \\
\hline 11:13:09 PM & Visibility limited - room 303 \\
\hline $11: 13: 10 \mathrm{PM}$ & Toxic/thermal hazard - room 313 \\
\hline $11: 13: 19 \mathrm{PM}$ & Visibility limited - section A-3 \\
\hline 11:14:09 PM & Visibility limited - section E-3 \\
\hline $11: 14: 10 \mathrm{PM}$ & Visibility limited - room 386 \\
\hline $11: 14: 11 \mathrm{PM}$ & Visibility limited - room 387 \\
\hline 11:14:12 PM & Visibility limited - section B-3 \\
\hline
\end{tabular}


Table 2 Event List for Building Break In and Set Fire scenario

Event Time Description of event

\begin{tabular}{|c|c|}
\hline 4:38:44 PM & Unauthorized door open - level 1 \\
\hline 4:39:04 PM & Elevator 1 occupied \\
\hline 4:39:14 PM & Elevator 1 level 2 \\
\hline 4:39:24 PM & Elevator 1 level 3 \\
\hline 4:39:29 PM & Elevator 1 unoccupied \\
\hline 4:39:30 PM & Motion sensor - level 3-226 - hall 3a \\
\hline 4:39:32 PM & Motion sensor - level 3-226- hall 3a \\
\hline 4:40:27 PM & Unauthorized door open - level 3 - 226 - A306 \\
\hline 4:40:32 PM & Motion sensor - level 3-226-A306 \\
\hline 4:40:52 PM & Motion sensor - level 3-226-A305 \\
\hline 4:41:32 PM & Potential hazard - level 3-226-B305 \\
\hline 4:42:33 PM & Heat sensor on - level $3-226-\mathrm{B} 305$ \\
\hline 4:43:28 PM & Unauthorized door opened - level $3-226-$ B305 \\
\hline 4:44:10 PM & Motion sensor - level $3-226-$ hall $3 b$ \\
\hline 4:44:25 PM & Unauthorized door opened - level $3-226-$ stair 23 \\
\hline 4:44:35 PM & Heat sensor on - level $3-226-$ A306 \\
\hline 4:44:36 PM & Visibility limited - level 3-226-B305 \\
\hline 4:45:05 PM & Heat sensor on - level $3-226-$ hall $3 b$ \\
\hline 4:45:06 PM & Unauthorized door open - level $1-226$ - stair 11 \\
\hline $4: 45: 15 \mathrm{PM}$ & Visibility limited - level $3-226-$ A306 \\
\hline 4:45:58 PM & Toxic/thermal hazard - level 3 - 226 - B305 \\
\hline 4:46:08 PM & Toxic/thermal hazard - level 3 - 226 - A306 \\
\hline 4:46:09 PM & Heat sensor on - level $3-226-$ hall $3 a$ \\
\hline 4:46:50 PM & Flashover conditions - level 3-226-B305 \\
\hline 4:46:51 PM & Heat sensor on - level $3-226-$ hall 31 \\
\hline 4:47:00 PM & Toxic/thermal hazard - level $3-226$ - hall $3 b$ \\
\hline 4:47:01 PM & Heat sensor on - level $3-226-$ hall 32 \\
\hline 4:47:02 PM & Potential hazard - level $3-226-$ hall 31 \\
\hline 4:47:04 PM & Potential hazard - level $3-226-$ hall 32 \\
\hline 4:48:07 PM & Heat sensor on - level $3-226-\mathrm{B} 302$ \\
\hline
\end{tabular}


Table 3 Event list for Fire in a Two Story Single Family Dwelling scenario

Event Time Description of event

\begin{tabular}{|c|c|}
\hline 11:27:01 PM & Heat sensor on - level 2 - bedroom 1 \\
\hline 11:29:03 PM & Potential hazard - level 2 - bedroom 1 \\
\hline 11:29:37 PM & Visibility limited - level 2 - bedroom 2 \\
\hline 11:30:30 PM & Heat sensor on - level 2 - second hallway \\
\hline 11:30:31 PM & Visibility limited - level 2 - second hallway \\
\hline $11: 31: 26 \mathrm{PM}$ & Toxic/thermal hazard - level 2 - bedroom 1 \\
\hline 11:32:06 PM & Visibility limited - level 2 - bath 2 \\
\hline $11: 32: 26 \mathrm{PM}$ & Visibility limited - level 2 - bedroom 3 \\
\hline 11:32:36 PM & Toxic/thermal hazard - level 2 - bath 2 \\
\hline $11: 32: 37 \mathrm{PM}$ & Visibility limited - level 2 - bedroom 2 \\
\hline 11:32:46 PM & Heat sensor on - level 2 - master bedroom \\
\hline 11:32:47 PM & Visibility limited - level 2 - master bedroom \\
\hline 11:32:56 PM & Visibility limited - level 1 - kitchen \\
\hline 11:32:57 PM & Visibility limited - level 1 - bath 1 \\
\hline 11:32:58 PM & Toxic/thermal hazard - level 2 - bedroom 2 \\
\hline 11:32:59 PM & Toxic/thermal hazard - level 2 - bedroom 3 \\
\hline $11: 33: 28 \mathrm{PM}$ & Visibility limited - level 2 - closet 6 \\
\hline 11:33:38 PM & Visibility limited - level 1 - living room \\
\hline 11:33:39 PM & Visibility limited - level 1 - kitchen \\
\hline 11:33:40 PM & Visibility limited - level 1 - bath 1 \\
\hline 11:33:41 PM & Visibility limited - level 2 - master bath \\
\hline $11: 33: 42 \mathrm{PM}$ & Toxic/thermal hazard - level $2-$ closet 6 \\
\hline $11: 33: 43 \mathrm{PM}$ & Flashover conditions - level 2 - bedroom 1 \\
\hline 11:33:48 PM & Visibility limited - level 1 - dining room \\
\hline 11:33:49 PM & Visibility limited - level 1 - study \\
\hline 11:33:57 PM & Visibility limited - level 1 - family room \\
\hline 11:33:58 PM & Toxic/thermal hazard - level 2 - master bath \\
\hline 11:34:07 PM & Toxic/thermal hazard - level 2 - master bedroom \\
\hline
\end{tabular}


Stage - No Police - No

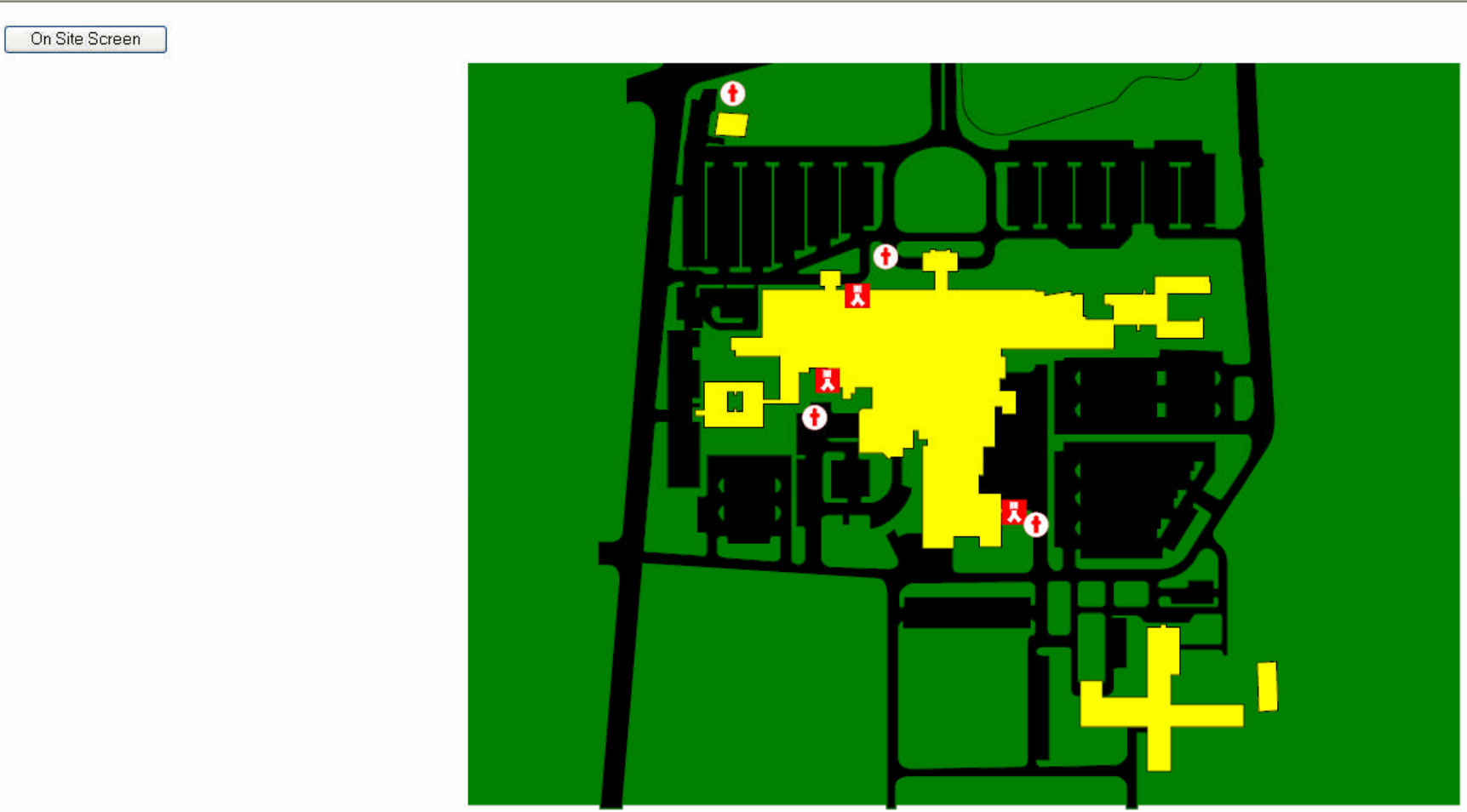

Figure 1 "En Route" screen for the hospital fire scenario. The button on the left side of the figure titled "On Site Screen" allowed the user to toggle back and forth between the "En Route" and "On Site" screens. 


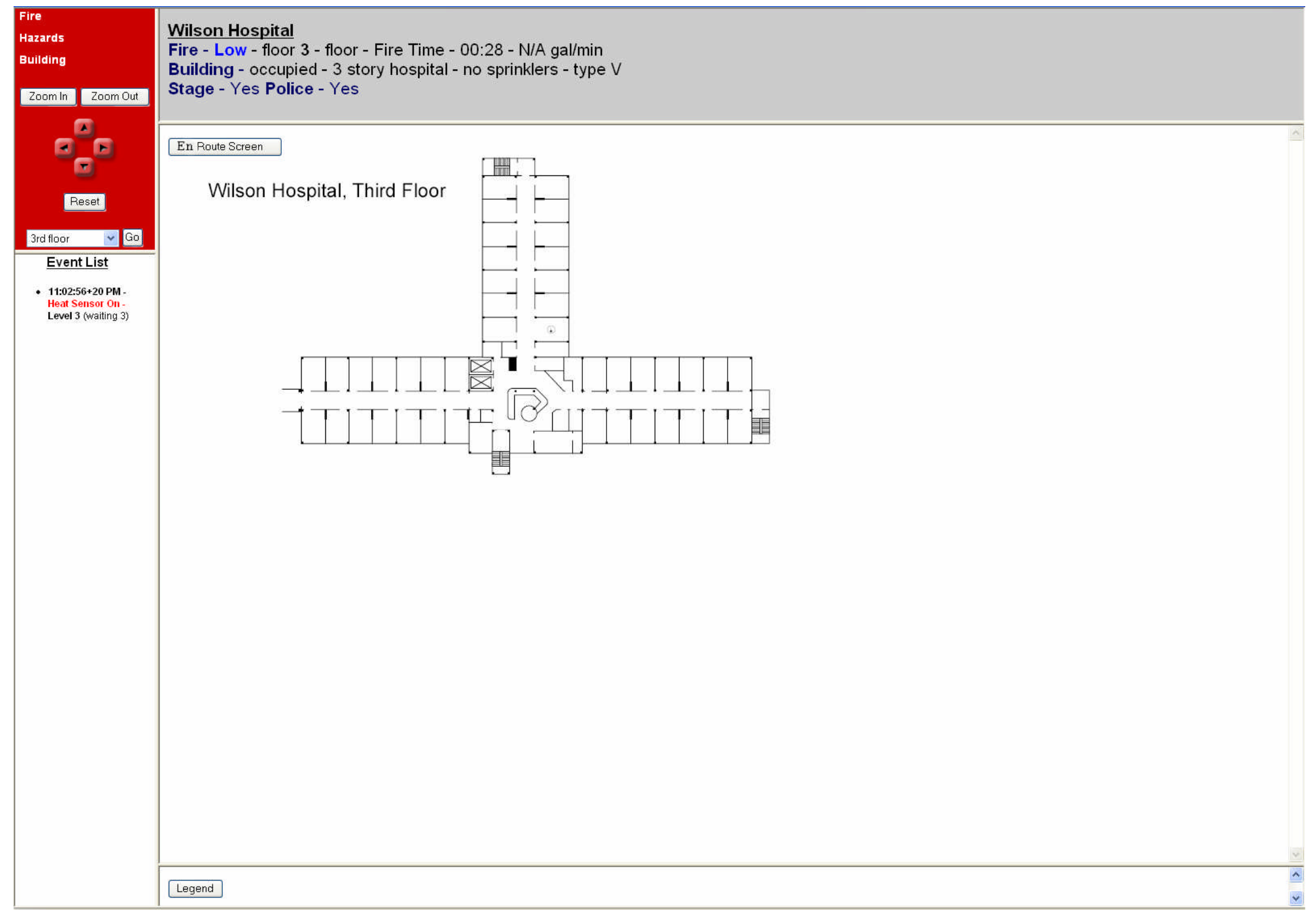

Figure 2 "On Site" screen for the hospital fire scenario after the first heat sensor has activated. The button on the left side of the figure titled "En Route Screen" allowed the user to toggle back and forth between the "En Route" and "On Site" screens. 


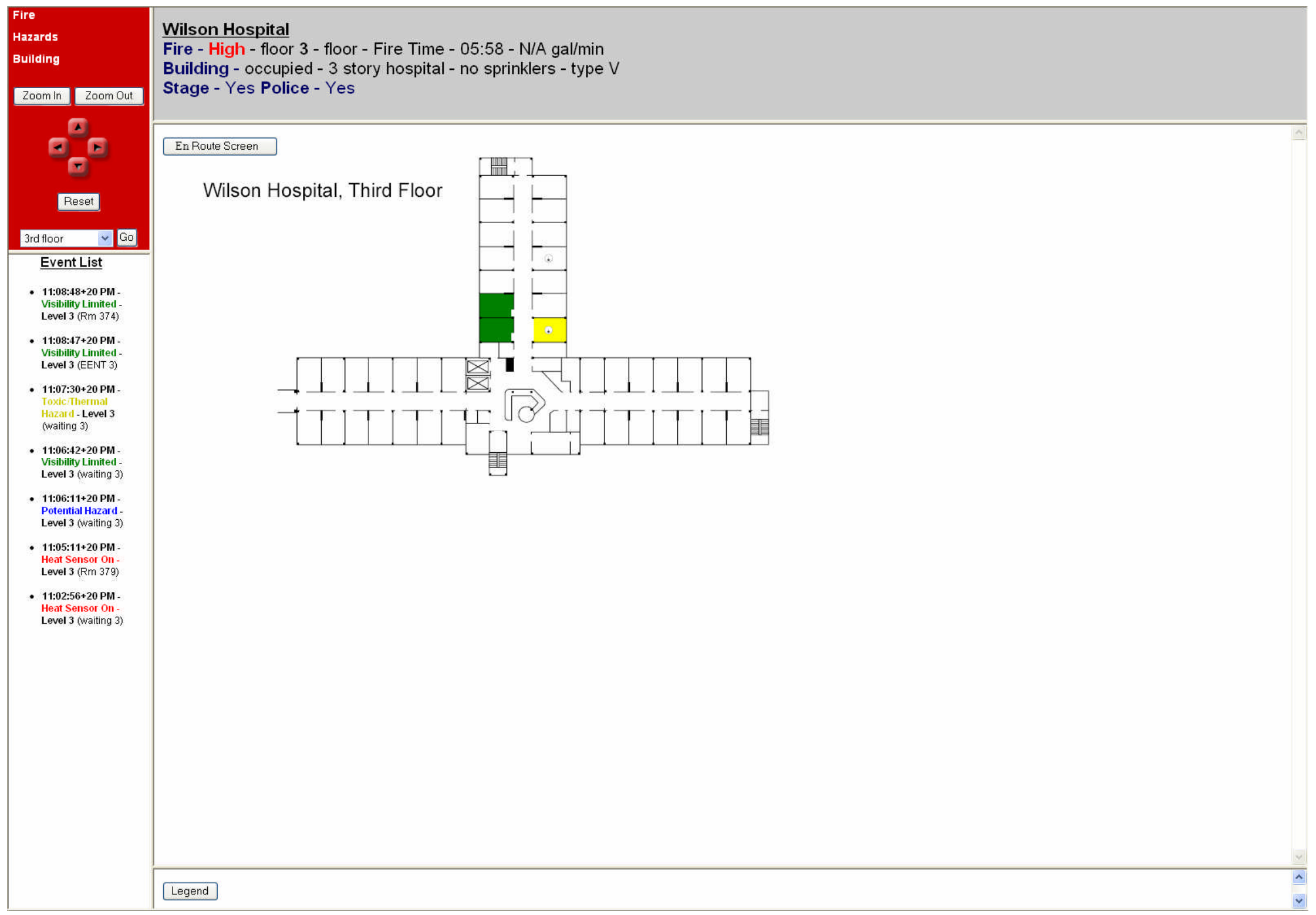

Figure 3 "On Site" screen for the hospital fire scenario after seven events have been listed in the event list. The button on the left side of the figure titled "En Route Screen" allowed the user to toggle back and forth between the "En Route" and "On Site" screens. 
Building 226, NIST, Gaithersburg MD

Fire - N/A - N/A floor - N/A - Fire Time N/A - N/A gal/min

Building - occupied 40 - 3 story laboratory - no sprinklers - type $V$

Stage - No Police - No

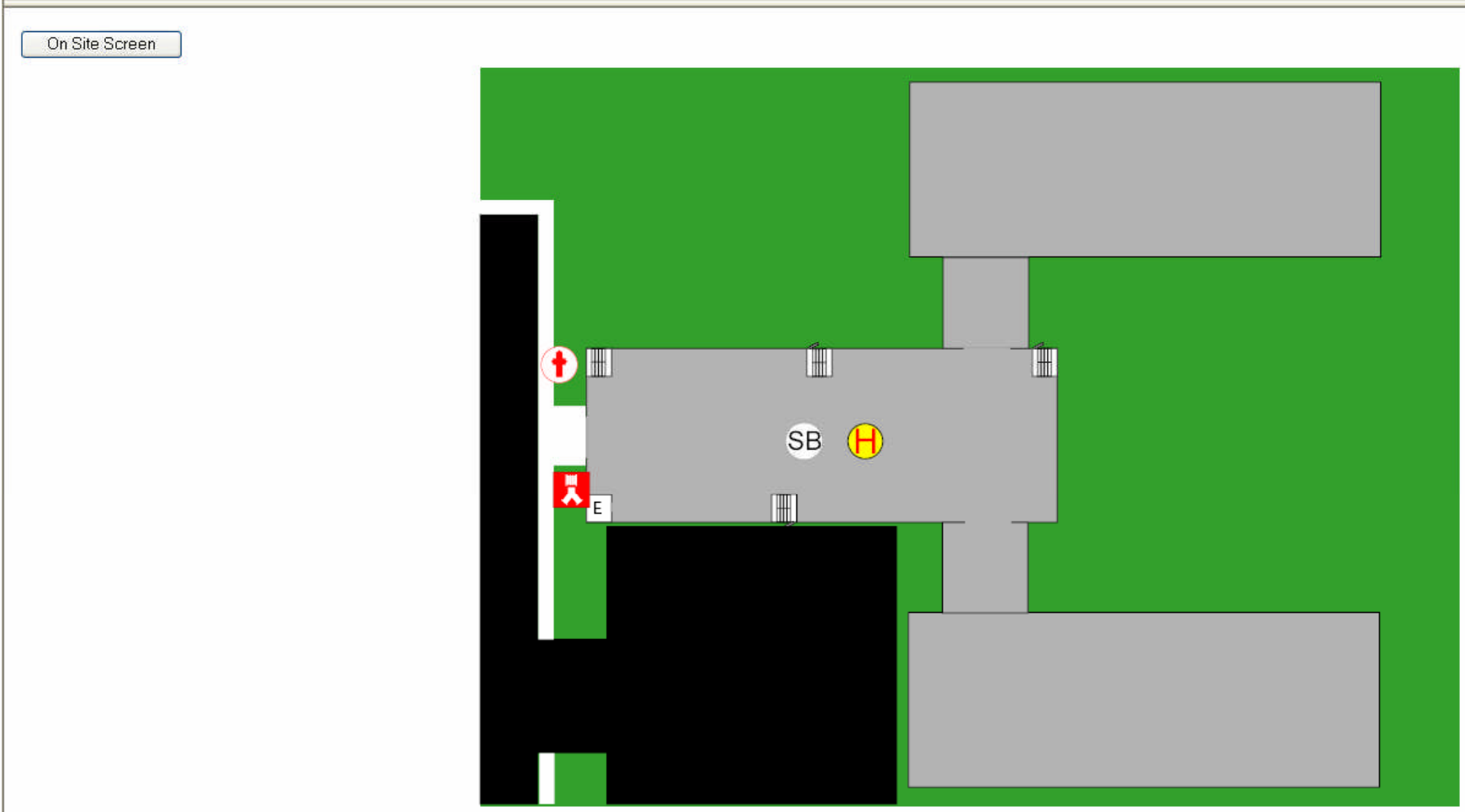

Figure 4 "En Route" screen for Building Break In and Set Fire scenario. The button on the left side of the figure titled "On Site Screen" allowed the user to toggle back and forth between the "En Route" and "On Site" screens. 


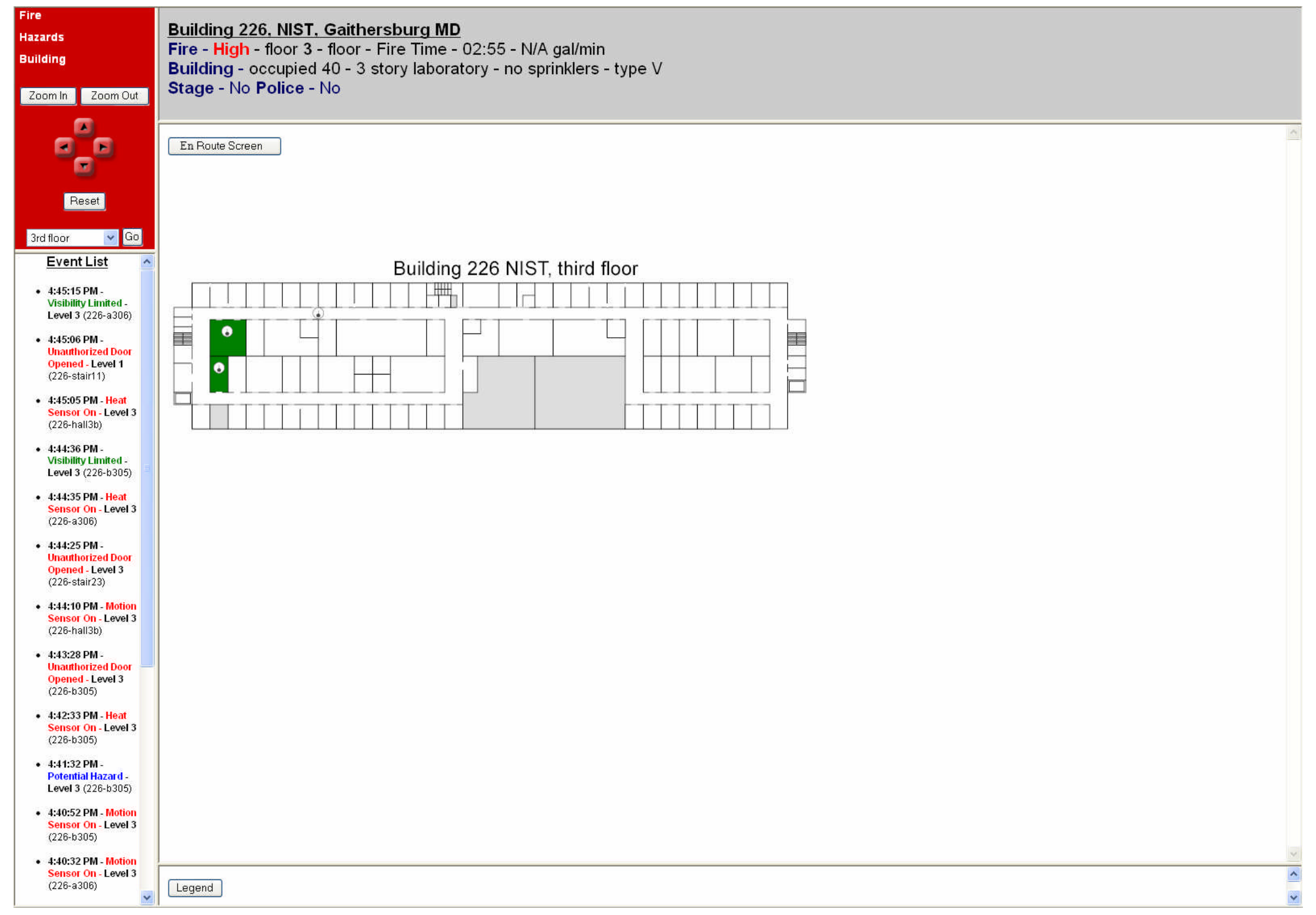

Figure 5 "On Site" screen for Building Break In and Set Fire scenario. The button on the left side of the figure titled "En Route Screen" allowed the user to toggle back and forth between the "En Route" and "On Site" screens. 


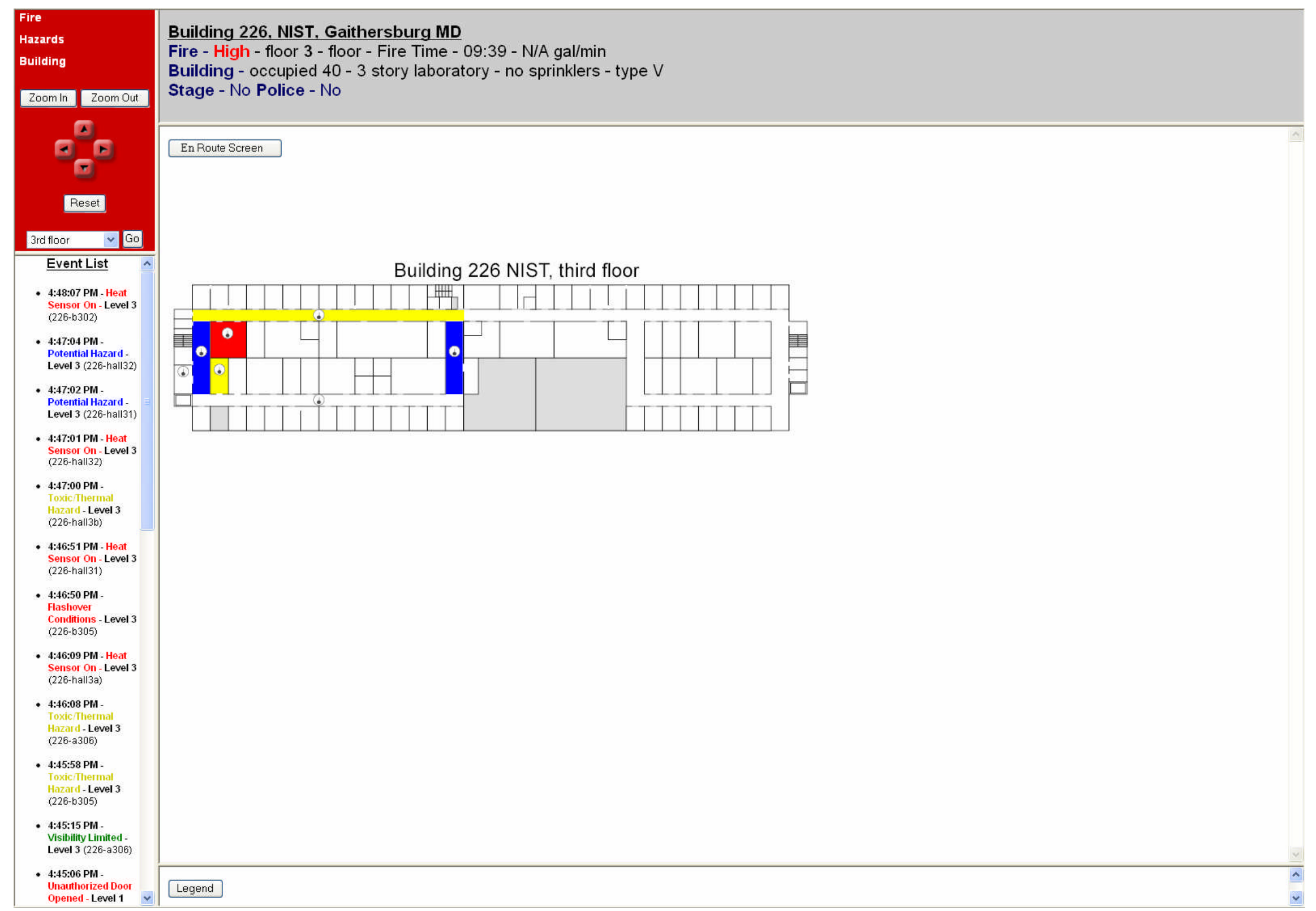

Figure 6 Final "On Site" screen for Building Break In and Set Fire scenario. The button on the left side of the figure titled "En Route Screen" allowed the user to toggle back and forth between the "En Route" and "On Site" screens. 


\section{Anywhere Road}

Fire - N/A - floor N/A - N/A - Fire Time - N/A - N/A gal/min

Building - occupied - 2 story single family with basement - no sprinklers - type $V$

Stage - No Police - No

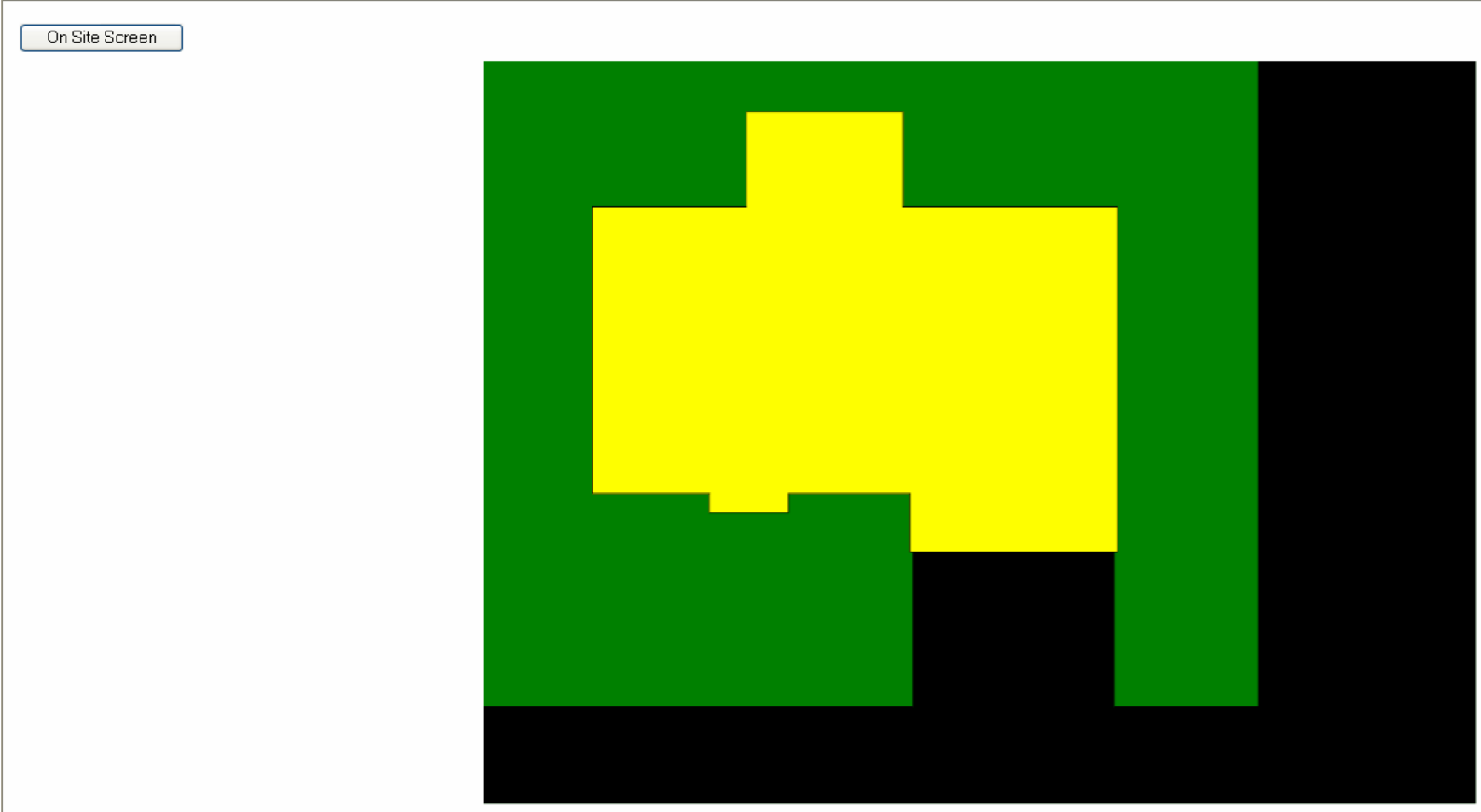

Figure 7 "En Route" screen for the Fire in a Two Story Single Family Dwelling scenario. The button on the left side of the figure titled "On Site Screen" allowed the user to toggle back and forth between the "En Route" and "On Site" screens. 


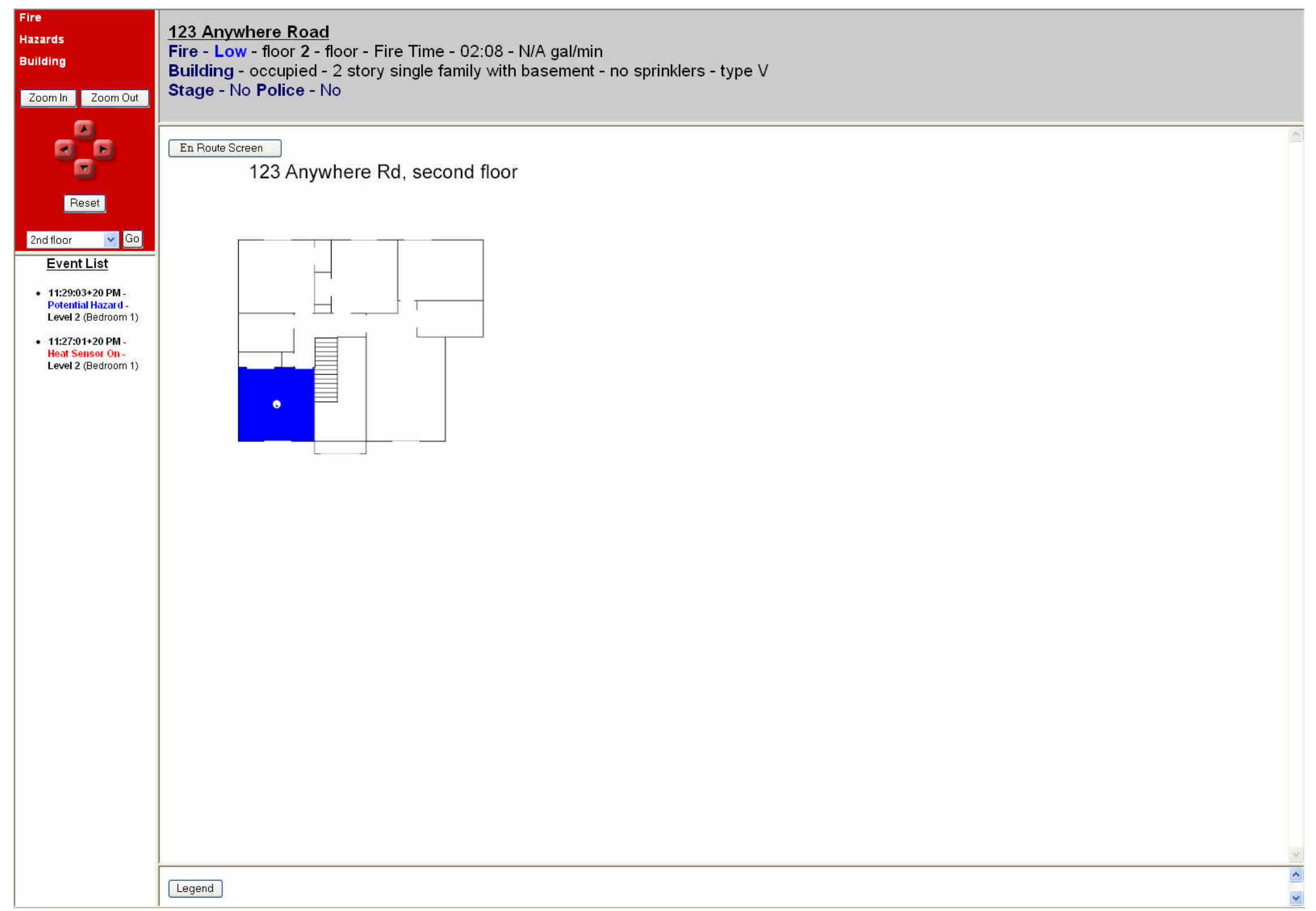

Figure 8 "On Site" screen for the Fire in a Two Story Single Family Dwelling scenario. The button on the left side of the figure titled "En Route Screen" allowed the user to toggle back and forth between the "En Route" and "On Site" screens. 


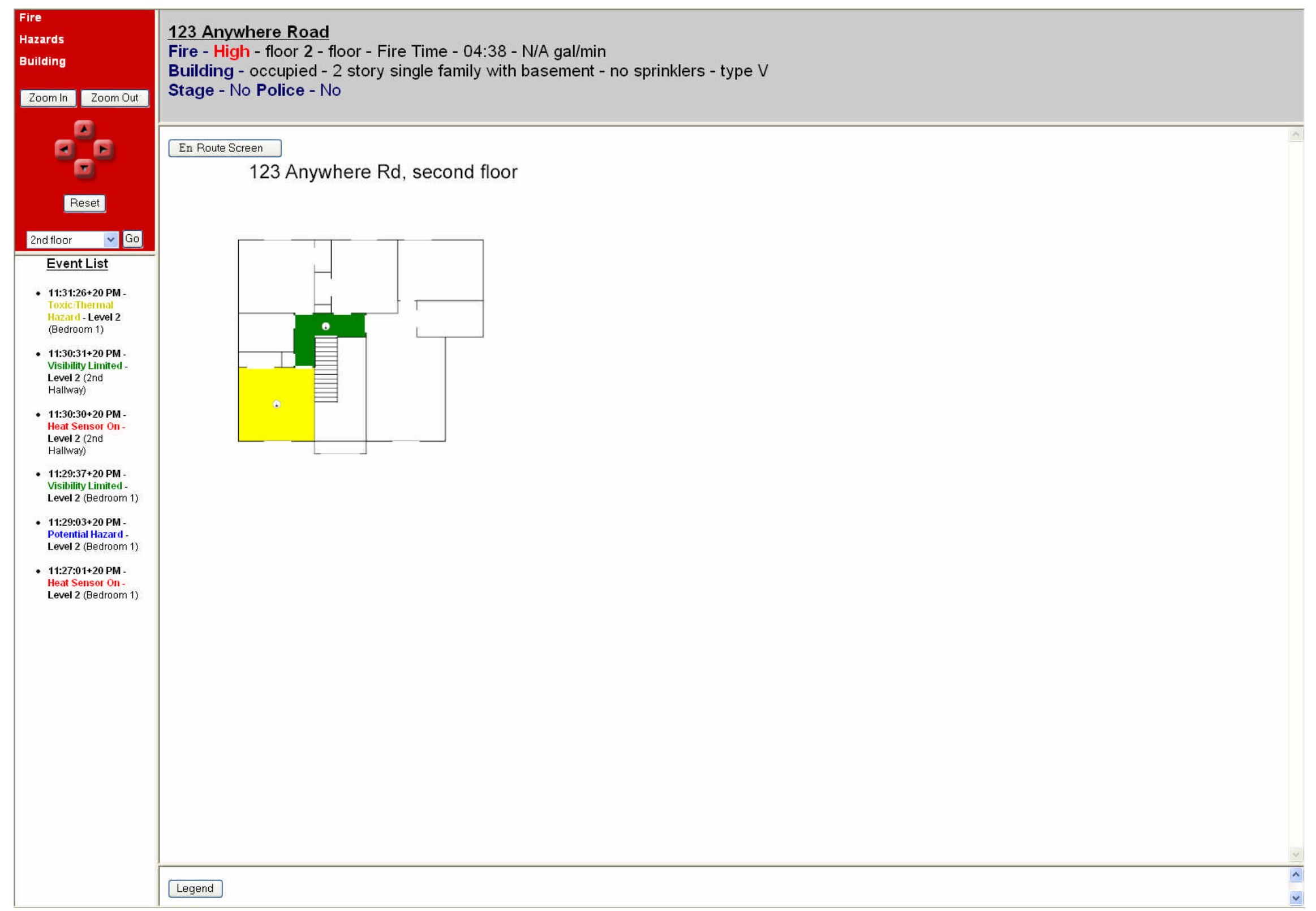

Figure 9 "On Site" screen for the Fire in a Two Story Single Family Dwelling scenario. The button on the left side of the figure titled "En Route Screen" allowed the user to toggle back and forth between the "En Route" and "On Site" screens. 


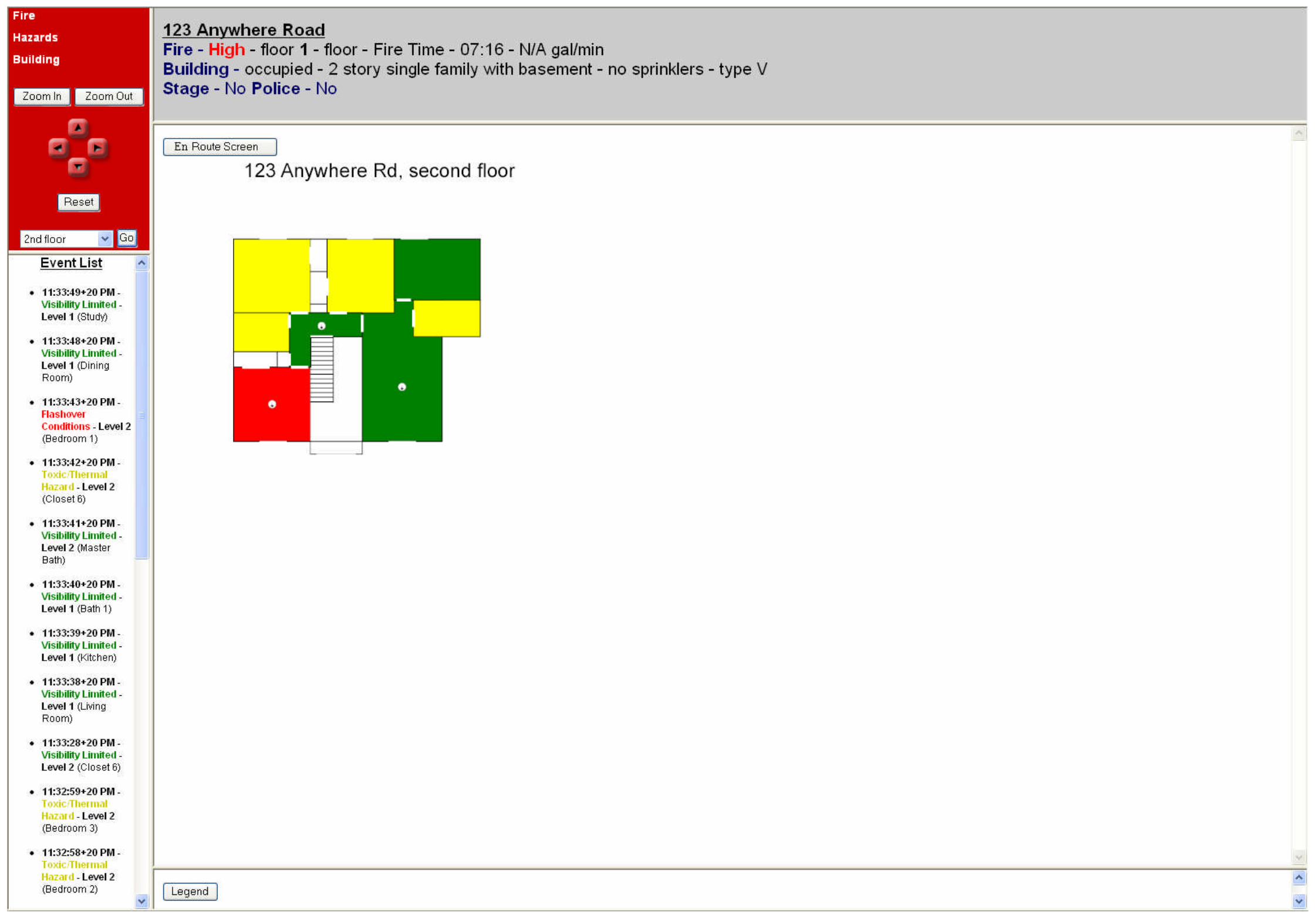

Figure 10 Final "On Site" screen for the Fire in a Two Story Single Family Dwelling scenario. The button on the left side of the figure titled "En Route Screen" allowed the user to toggle back and forth between the "En Route" and "On Site" screens. 


\section{Democracy Blvc}

Fire - N/A - floor N/A - N/A - Fire Time - N/A - N/A gal/min

Building - occupied - 2 story commercial - sprinklers - type $V$

Stage - No Police - No

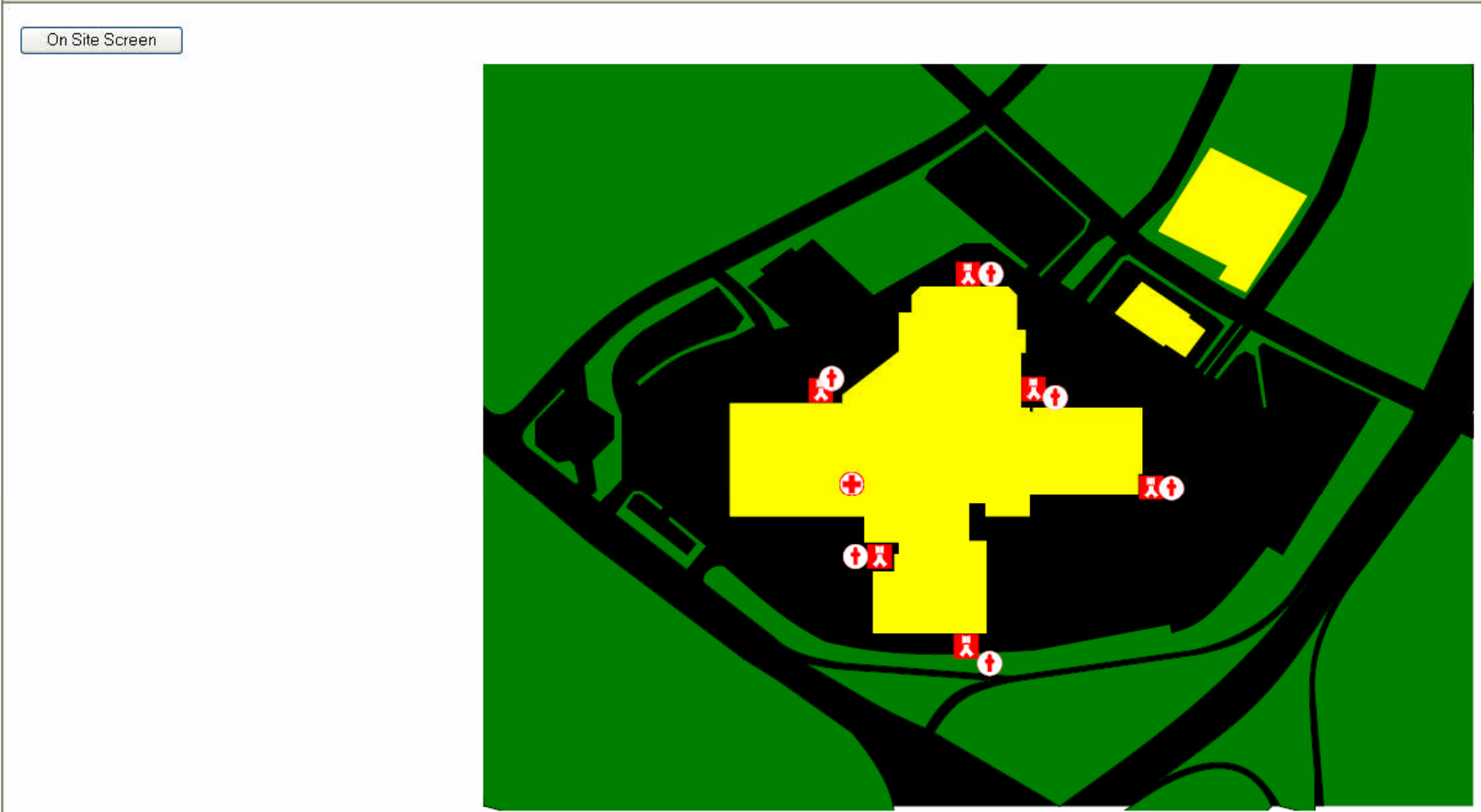

Figure 11 "En Route" screen for the Emergency Medical Call to a Shopping Mall scenario. The button on the left side of the figure titled "On Site Screen" allowed the user to toggle back and forth between the "En Route" and "On Site" screens. 


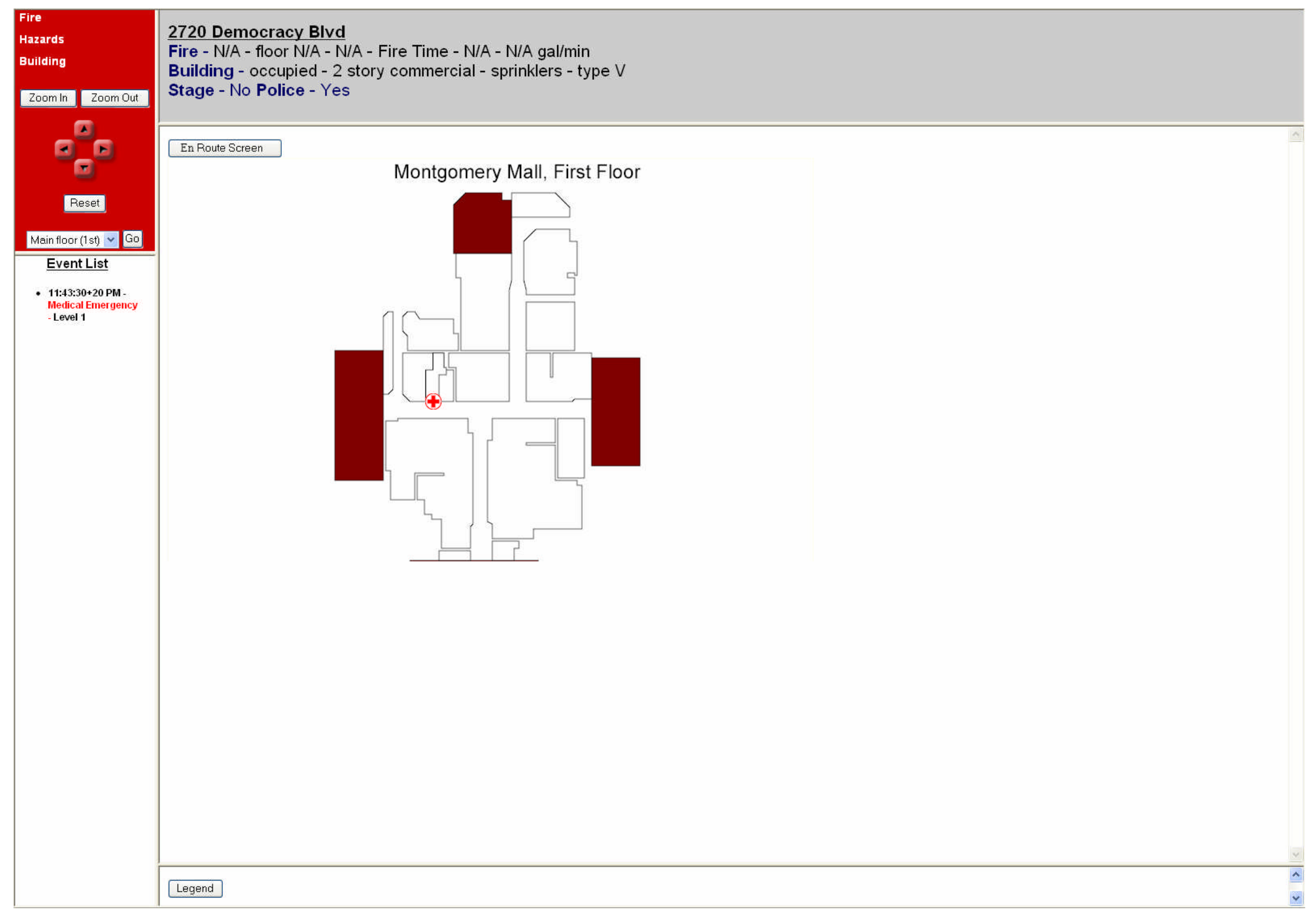

Figure 12 "On Site" screen for the Emergency Medical Call to a Shopping Mall scenario. The button on the left side of the figure titled "En Route Screen" allowed the user to toggle back and forth between the "En Route" and "On Site" screens. 


\section{Appendix A - Workshop Attendees}

Name

Mr. Jason Averill

Captain Danny Baker

Lieutenant Carey Beall

Captain Don Bowers

Ms. Lori Brassell

Chief John Burger

Captain Charles Davis

Dr. William Davis

Chief William Fitzgerald

Captain Ray Henry

Dr. David Holmberg

Ms. Jodi Kostecki

Ms. Jessica Kratchman

Ms. Erica Kuligowski

Lieutenant Dallas Lipp

Mr. Jack Murphy

Mr. Paul Reneke

Mr. Robert Vettori

Captain Bill Walker

Chief John White
Affiliation

NIST Building and Fire Research Lab

National Institute of Standards and Technology Fire Department

Montgomery County Fire and Rescue (MD)

Fairfax County Fire and Rescue (VA)

NIST Building and Fire Research Lab

District of Columbia Fire Department

Arlington County Fire Department (VA)

NIST Building and Fire Research Lab

District of Columbia Fire Department

Montgomery County Fire and Rescue (MD)

NIST Building and Fire Research Lab

NIST Building and Fire Research Lab

NIST Building and Fire Research Lab

NIST Building and Fire Research Lab

Montgomery County Fire and Rescue (MD)

New York City Fire Safety Directors

NIST Building and Fire Research Lab

NIST Building and Fire Research Lab

Prince William County Fire and Rescue (VA)

Arlington County Fire Department (VA) 


\section{Appendix B - Workshop Agenda \\ NIST Fire Service Feedback Workshop \\ NIST Fire Conference Room \\ Building 224, Room B 245 \\ July 26,2005 \\ 9 a.m. to 4 p.m. \\ Agenda}

Morning Session: Evaluation of Tactical Decision Aids Interface

8:30 - 9:00 a.m. $\quad$ Light refreshments

9:00 - 9:15 a.m. Introductions and Workshop Overview William Davis

9:15 - 9:30 a.m. Discussion of Tactical Decision Aids Project David Holmberg

9:30 - 10:45 a.m. Hands-on evaluation of TDA Interface Robert Vettori

10:45 - 11:00 a.m. Morning Break

11:00 - Noon $\quad$ Interface Evaluation, Continued

Noon - 1:00 p.m. $\quad$ Lunch at NIST Lunch Club, Building 101

Afternoon Session: Open Discussion of Fire Service and Occupant Interactions

1:00 - 1:30 p.m. Fire Service Access to Hi-rise Buildings Jason Averill

1:30 - 2:00 p.m. Evacuation of Mobility Challenged Occupants Erica Kuligowski

2:00 - 2:30 p.m. Large Incident Information Flow Jason Averill

2:30 - 2:45 p.m. Afternoon Break

2:45 - 3:15 p.m. Defend-In-Place or Full Building Evacuation? Erica Kuligowski

3:15 - 4:00 p.m. Continued Discussion and Wrap-up 


\section{References}

1 Jones, W., Holmberg, D., Davis, W., Evans, D., Bushby, S., and Reed, K., Workshop to Define Information Needed by Emergency Responders during Building Emergencies, NISTIR 7193, January 2005.

2 "ANSI/ASHRAE Standard 135-2004 BACnet-A Data Communication Protocol for Building Automation and Control Networks", 2005 